\title{
A CIÊNCIA PODE TUDO? CONSIDERAÇÕES ÉTICAS SOBRE TECNOBIOCIÊNCIA E VALORES A PARTIR DE HANS JONAS
}

\author{
Jelson Roberto de Oliveira ${ }^{1}$ \\ Pontifícia Universidade Católica do Paraná (PUC/PR) \\ (D) https://orcid.org/0000-0002-2362-0494 \\ E-mail: jelsono@yahoo.com.br

\section{Grégori de Souza ${ }^{2}$} \\ Pontifícia Universidade Católica do Paraná (PUC/PR) \\ https://orcid.org/0000-0001-9995-3124 \\ E-mail: gregoridesouza@hotmail.com
}

\section{RESUMO:}

Nesse artigo pretende-se analisar a relação entre ciência e valores a partir da filosofia de Hans Jonas. Parte-se de uma análise da mudança identificada pelo autor no que tange ao novo status do saber na modernidade, que dá origem à chamada tecnobiociência, nascida da articulação entre saber e fazer, em vista de um novo poder. Trata-se de mostrar como a antiga formulação do conhecimento como contemplação deu lugar à ideia utilitarista de conhecimento como exploração, embora em tal versão, mantenha-se a reivindicação de neutralidade e de liberdade absoluta, própria da antiga ilha moral representada pelo saber pré-moderno. Jonas argumenta a favor de uma articulação da tecnobiociência com a ética, a fim de fornecer os valores capazes de orientar o saber, o fazer e o poder na civilização tecnológica.

PALAVRAS-CHAVE: Tecnobiociência; Valores; Ciência; Hans Jonas; Responsabilidade.

\section{CAN SCIENCE DO EVERYTHING? ETHICAL CONSIDERATIONS ON TECHNOBIOCIENCE AND VALUES BASED ON THE HANS JONAS' PHILOSOPHY}

\begin{abstract}
:
In this article we intend to analyze the relationship between science and values from the philosophy of Hans Jonas. It starts with an analysis of the change identified by the author with regard to the new status of knowledge in modernity, which gives rise to the so-called technobioscience, born from the articulation between knowing and doing, in view of a new power. It is about showing how the old formulation of knowledge as contemplation gave way to the utilitarian idea of knowledge as exploration, although in such a version, the claim of neutrality and absolute freedom is maintained, characteristic of the old moral island represented by knowledge pre-modern. Jonas argues in favor of an articulation of technobioscience with ethics, in order to provide the values capable of guiding knowing, doing and power in technological civilization.
\end{abstract}

KEYWORDS: Technobioscience; Values; Science; Hans Jonas; Responsibility.

\footnotetext{
${ }^{1}$ Doutor(a) em Filosofia prela Universidade Federal de São Carlos (UFSCAR), São Carlos - SP, Brasil. Professor(a) da Pontifícia Universidade Católica do Paraná (PUC/PR), Curitiba - PR, Brasil.

${ }^{2}$ Mestrando(a) em Filosofia na Pontifícia Universidade Católica do Paraná (PUC/PR), Curitiba - PR, Brasil. Bolsista do(a): Coordenação de Aperfeiçoamento de Pessoal de Nível Superior(CAPES), Brasil.
}

OLIVEIRA, Jelson Roberto de.; SOUZA, Grégori de. A ciência pode tudo? Considerações éticas sobre tecnobiociência e valores a partir de Hans Jonas. Griot : Revista de Filosofia, Amargosa - BA, v.21 n.3, p.164-173, outubro, 2021. 


\title{
Introdução
}

\begin{abstract}
Vivemos todos com a consciência concreta de não podermos dizer Não para a ciência, a tecnologia e a medicina. Mesmo se quiséssemos, não podemos dizer Não para o complexo biomédico que se apropria de nossos corpos, define nosso estado de saúde e nos posiciona em um gradiente de adaptação, que vai do temporariamente capacitado até o permanentemente incapacitado. Não podemos dizer Não ao complexo de informação empresarial/governamental que se conecta a nossos números de previdência social, carteiras de motorista, contas-corrente, cartões de crédito, cadastros de pessoas físicas, telefones, rádios, televisões, correio eletrônico e outros vetores tecnológicos de identidade. Não podemos dizer Não à experiência da ciência, da tecnologia e da medicina, que atua coletivamente como centro disciplinador que policia outros significados e outras relações de poder na vida contemporânea. Mas como podemos continuar compreendendo e dando conta destas profundas e permanentes presenças em nossos corpos, nossas pessoas, nossas ideias de nós-próprios? Mais ainda, como compreenderemos nossa frequente e intensa ânsia para dizer Sim?
\end{abstract}

Com essa incômoda constatação, Joseph Dumit (1997, p. 5) expressou algumas das preocupações centrais de quem se dedica, nos últimos dois séculos, a estudar os avanços da tecnologia e, em especial, aqueles que dizem respeito à conjugação entre tecnologia, ciência e ética. E isso está ligado ao papel do cientista ou do agente tecnológico, em sua vocação e responsabilidade que se traduz em uma pergunta de tipo ética (essa ciência do Sim e do Não).

Ora, por muito tempo o conhecimento foi sustentado pelo ideal da contemplação. Era função do pesquisador pré-moderno se deleitar com seus próprios pensamentos e, assim, a esfera da contemplação estava definitivamente separada da esfera da ação, o que tornava o conhecimento uma espécie de ilha moral: na medida em que ele não dizia respeito à ação, mantinha-se separado das preocupações éticas, dado que seu único mandamento é aquele do avanço de suas próprias conjecturas. Consequentemente, a única questão valorativa para o conhecimento é ele mesmo, detido que estava em seu horizonte de expansão e conquistas. $O$ único valor é aumentar ainda mais o campo do conhecido sem que nisso estivesse implicado qualquer elemento ético no que diz respeito, por exemplo, aos efeitos da ação do homem teórico na busca pelo saber.

Ora, essa teria sido, precisamente, a mudança trazida pela modernidade no que diz respeito à nova tarefa daquilo que podemos chamar, efetivamente, de ciência (que inclui uma metodologia nova, além de uma especificação do objeto). O filósofo alemão Hans Jonas chama essa mudança de um "novo status do saber na hierarquia do espírito" (TME, 38) ${ }^{3}$, resultado da "ascensão da técnica à posição de uma das principais tarefas da humanidade". Ora, na medida em que a ciência se vincula de forma irreversível com a atividade técnica e essa, por sua vez, lhe fornece os mecanismos, procedimentos e dispositivos para o avanço do conhecimento, pode-se dizer que o saber deixa a sua antiga ilha moral, para tornar-se, sempre, uma forma de intervenção no mundo, dado que [1] o novo método implica sempre um tipo de experimento com o mundo, [2] consequentemente, que o experimento é sempre uma ação e [3] tal ação (um fazer, portanto) torna-se um aspecto indissociável do saber para tornar-se um poder. Assim, a marca da ciência moderna é uma articulação estreita entre a "teoria" e a "prática", antes separada pela hierarquia e a nobreza da contemplação abstrata e agora vinculadas pelo saber-fazer-poder científico. No novo cenário científico, segundo Jonas, não haveria mais separação entre saber e fazer, tendo

\footnotetext{
3 No presente artigo usaremos as seguintes siglas para a citação das obras de Hans Jonas: TME (Técnica, Medicina e Ética: sobre a prática do princípio responsabilidade e PR (O Princípio Responsabilidade: ensaio de uma ética para a civilização tecnológica). As abreviaturas são seguidas do número da página conforme a obra que se encontra nas referências.
} 
desaparecido (ou pelo menos enfraquecido) o valor do conhecimento puro, que deu lugar ao utilitarismo e às "necessidades comuns": "trocou-se nobreza por utilidade", afirma Jonas (TME, $39)$.

\title{
0 advento da tecnobiociência ${ }^{4}$
}

Jonas chama atenção para o fato de que essa mudança foi a marca do programa baconiano em oposição ao modelo aristotélico: a ideia de contemplação cede lugar à de exploração do mundo. A teoria deixa de lado o seu prestígio para avançar ao campo do "esforço transutilitário" que a dispõe sempre como um serviço em benefício do mundo exterior. Essa "aplicação" imediata do saber é a marca da atividade tecnocientífica, adulada pelas novos dispositivos e processos que passam a "revestir sua infinita atividade com a dignidade dos mais altos objetivos", considerando "fim" aquilo que era "meio", a tecnologia passa a ser vista, por isso, como "o verdadeiro destino da humanidade" (TME, 40). Cobrada pela sua capacidade de inflar o progresso social, a tecnologia passa a representar o afã utópico que faz o ser humano avançar "de poder a poder". Ocorre que esse afã (assumido como tarefa prática) quer manter os antigos "benefícios" da contemplação, ou seja, pretende permanecer como aquela ilha moral antiga, dando de ombros para os novos desafios trazidos pela multiplicada ambivalência e magnitude no tempo e no espaço da ação técnica. É isso que explicaria, por exemplo, a reivindicação de liberdade absoluta por parte da tecnociência contemporânea: fechando os olhos para os perigos e ameaças irreversíveis contidas nas suas próprias atividades, ela compreende-se livre para realizar todos os procedimentos necessários para corresponder a esse ideal de progresso indefinido que ela mesma se impôs, estimulada pela própria sociedade contemporânea. Como ilha moral, a tecnobiociência reivindica aquela antiga inocência perdida do conhecimento contemplativo, pautando-se pela utopia do progresso tecnológico que vislumbra em suas ações apenas aspectos positivos e benéficos. Isso porque, "para alcançar seus próprios objetivos teóricos, a ciência necessitava de uma tecnologia cada vez mais refinada e fisicamente forte como ferramenta que se produz a si mesma" (TME, 38). Essa é a "grande virada" descrita por Jonas nas seguintes palavras:

\begin{abstract}
A grande virada é marcada pelo uso sempre mais frequente do epíteto laudatório "novo" para uma variedade sempre maior de iniciativas humanas - na arte, na ação e no pensamento. Essa moda linguística seria grave ou fútil dependendo do caso, nos diz uma série de coisas. A elevação do termo a atributo laudatório denuncia certo cansaço, até mesmo certa impaciência com as formas de pensar e de viver até então dominantes. $O$ respeito pela sabedoria do passado é substituído pela suspeita de um erro inveterado e pela desconfiança de uma autoridade inerte. Isso vem acompanhado de um novo estado de autoconfiança, de uma firme convicção de que nós modernos estamos mais bem equipados do que os antigos - e certamente melhor do que nossos antecessores imediatos - para descobrir a verdade e melhorar muitas coisas (SDD, 81)
\end{abstract}

É essa, precisamente, a problemática levantada por Hans Jonas, tanto em sua obra magna, Das Prinzip Verantwortung (1979) quando na sua aplicação prática ao campo das biotecnologias, conforme Technik, Medizin und Ethik (1985). Jonas quer, justamente, demonstrar como o novo status do saber (marcado por novas dimensões de espaço e tempo, dado o aumento da magnitude e ambivalência dos novos poderes) rompe com a antiga definição de um saber meramente contemplativo, colocando-o no campo do fazer e, portanto, exigindo reflexões éticas capazes de

\footnotetext{
4 Usaremos nesse trabalho o conceito de tecnobiociência para evocar a articulação, descrita por Jonas, entre a técnica e a ciência e, ao mesmo tempo, por uma biotecnologia e por uma biociência. Com isso, compreendemos a tecnobiociência como uma área de atuação que unifica a tecnologia, a ciência e a vida ou, melhor dizendo, a tecnologia e a ciência aplicadas sobre a vida.
} 
orientar o seu uso. Isso, em um tempo, como se sabe, em que a ética se encontra obnubilada pelo niilismo dos valores e diante de um cenário para o qual nenhuma das éticas tradicionais oferece alternativa.

\section{Da medicina à biotecnologia}

Para Jonas, não por acaso, a biotecnologia é o capítulo mais dramático porque precisamente ela tem o potencial de provocar imensos e irreversíveis impactos sobre a humanidade. Esse problema é descrito, pela sua gravidade, como um desafio de tipo metafísico, porque se trata de "desenhar nossos descendentes" (TME, 50), algo que deixa o campo da mera fantasia para ocupar os cientistas em muitos laboratórios ao redor do mundo. Trata-se de discutir o problema da "imagem do homem" a partir do qual a filosofia quebra o antigo "tabu inviolável" e encontra-se diante do "mais imperioso e mais urgente" desafio do pensamento: a "primeira tarefa cósmica" (TME, 50) da filosofia, pois o que está em jogo é a manutenção daquilo que é descrito como o "menos reconstruível": "torna-se uma obrigação transcendente do homem proteger o menos reconstruível, o mais insubstituível de todos os 'recursos': a incrivelmente rica dotação genética depositada pelas eras da evolução" (TME, 36).

Ora, poucos campos do saber foram mais afetados por essa mudança do que a medicina e, mais especificamente, a biotecnologia. Para Jonas, esse é o domínio mais recente do saber a sofrer os impactos da ação tecnológica, embora seja ele também, o campo no qual o saber nunca se desvencilhou das questões éticas: "todo o trato com o mundo extra-humano, isto é, todo o domínio da techne (habilidade) era - à exceção da medicina - eticamente neutro", escreve o autor no primeiro capítulo d'O princípio responsabilidade (PR, 35). É como exceção, portanto, que a medicina se manteve sempre no território da ação, no qual a techne nunca foi neutra, já que seu objeto sempre foi assunto ético, pois no fim, tratava-se sempre do ser humano e da busca por aquilo que poderia ser considerado o seu bem. A medicina, por isso, é o campo onde o ser humano não é apenas sujeito, mas também objeto do saber, ao tempo em que esse saber é sempre já adquirido e aplicado sobre um organismo, ou seja, é sempre já um fazer. Com o avanço da tecnologia também nesse campo, a biotecnologia testemunha as novas dimensões do agir humano trazidos pelo progresso tecnológico, fazendo com que o homo faber passasse a aplicar sobre si mesmo a sua arte, na perspectiva de "refabricar inventivamente o inventor e confeccionador de todo o resto" (PR, 57).

Se o conhecimento médico já era assunto de ética, portanto, agora, com os novos poderes da biotecnologia, essa condição se torna não apenas evidente, como urgente, na medida em que ela representa a "culminação de seus poderes, que pode muito bem significar a subjugação do homem", algo que passa a desafiar "o último esforço do pensamento ético" (PR, 57). O que está em jogo, agora, não é apenas o trabalho de cura (devolução de um organismo ao seu estado natural), mas de terapia melhorista (a alteração da natureza mesma do organismo, do ponto de vista do projeto de aperfeiçoamento/aprimoramento da "constituição humana"). E é precisamente nesse campo novo da biotecnologia que o problema da liberdade de pesquisa dever ser analisado, na perspetiva de que a ação seja eticamente avaliada, tanto em vista de sua orientação quanto da imposição de "freios voluntários" não apenas ao uso, mas também à conquista desses novos poderes.

\section{A [i]legítima liberdade da ciência}

No capítulo intitulado $A$ liberdade de pesquisa e o bem público, da sua obra Técnica, medicina e ética: sobre a prática do princípio responsabilidade (1985), Jonas apresenta aquilo que chamou de 
"ética territorial do campo científico" (TME, 102). Nela, o dever da ciência é ser coerente consigo mesma e com os outros, seguindo as regras e os métodos específicos de demonstração, não enganando a si e, sequer, a outros. Os mandatários são, portanto: "retidão e seriedade intelectuais" (TME, 102). Do ponto de vista ético, isso não seria nada mais, diz Jonas, que o estatuto de um bom cientista ao invés de um mau cientista. Além disso, outro dever cabível ao pesquisador pré-moderno era a comunicação de seus resultados e fundamentações à comunidade científica, outorgando à moral intracientífica uma dimensão social e pública.

Nesse sentido, o saber do pesquisador que, como dito, estava disposto apenas na esfera da contemplação, longe da esfera ativa que não atingia as atividades práticas do cotidiano, podia ser entendido como um bem privado, de posse interna daqueles que o exerciam. Sua difusão, ou passagem da subjetividade para a objetividade, tornava-se uma perigosa arma para o bem coletivo. Não por menos, em muitos momentos da história pudemos evidenciar a influência dos poderes públicos como a Igreja e o Estado intervindo no desenvolvimento do pensamento científico, por julgá-lo ameaçador para a ordem e o bem comum. Ou, no caso da Igreja, por "enfraquecer sua fé." (TME, 103). Por conseguinte, cabia àqueles poucos doutos da ciência a defesa contra o perigo do mundo externo, que a qualquer momento ameaçavam solapar ou tutelar os seus espíritos. Portanto, o máximo de poder que as ideias da ciência pré-moderna tinham era mais de convencer, do que de coagir a coletividade.

Hans Jonas analisa essa problemática de forma mais demorada no capítulo 5 de Técnica, medicina e ética, cujo título é justamente $A$ liberdade da pesquisa e o bem público. O filósofo recupera, nesse artigo publicado pela primeira vez em $1976^{5}$, a argumentação sobre a "fusão entre teoria e prática na ciência moderna" sob a perspectiva da ampliação da liberdade de pesquisa. Essa fusão é, precisamente, segundo Jonas, uma das marcas do pensamento moderno (ainda que tenha restado, como pano de fundo, aquilo que ele chama de "ficção da 'teoria pura' e sua “inocência' essencial" [TME, 104]) e é daí que deriva a reivindicação da liberdade ilimitada por parte da ciência, "cujo direito parece ser incondicionado, quer dizer, não limitado pelo possível conflito com outros direitos" (TME, 101). Essa pretensão reserva, de antemão, conforme Jonas, uma contradição, posto que uma tal liberdade só pode ser dada por uma instância que esteja fora do âmbito científico e seja garantida por um poder e uma posse que lhe são exteriores, enquanto a suposta "incondicionalidade da liberdade em pesquisa" só pode se apoiar em um tipo de pesquisa que esteja mantida no âmbito teórico, ou seja, externo ao âmbito da ação. Isso porque [1] a ciência hoje vive daquilo que Jonas chama de feedback intelectual fornecido por aqueles que desfrutam de suas possibilidades de aplicação; [2] o que lhe dá orientações para seguir é, justamente, esse potencial aplicativo; [3] toda ciência, para avançar, conta com o apoio da técnica na confecção de seus instrumentos físicos, que precisam ser cada vez mais avançados; e [4] ela conta com financiamento externo, dinheiro público e patrocínios que esperam por compensações e benefícios posteriores. Por consequência, toda ciência está orientada de fora, por interesses que lhe são alheios, exteriores a si mesma, e não apenas pela sua lógica interna ou pelas motivações próprias de seus pesquisadores. Diante desse cenário, como poderíamos falar de uma liberdade ilimitada?

O que Jonas quer demonstrar é que, no âmbito da ação, toda liberdade encontra-se diante da barreira da responsabilidade e que, sendo assim, reivindicar liberdade só faria sentido em um domínio teórico - justamente aquele domínio que a ciência moderna perdeu, na medida em que reduziu o saber ao fazer. Por esses motivos, para ele, à pesquisa não deveria ser autorizada nenhuma liberdade incondicional, dado que pode afetar de maneira decisiva a natureza em geral.

\footnotetext{
${ }^{5}$ A primeira versão desse texto foi publicada no The Hastings Center Report (6/4, 1976), com o título Freedom of a Scientific Inquiry and the Public Interest; outra versão, com o título Straddling the Boundaries of Theory and Practice, foi publicada em 1983 (Recombinant DNA: Science, Ethics, and Politic, ed. John Richards, Nova York, Academic Press).
} 
É como se Jonas estivesse dizendo que, enquanto cientistas, temos a total liberdade de pensar, mas não somos totalmente livres para agir.

Para Jonas, isso não significa impedir a verdade. Ao contrário, para ele a verdade é um "direito supremo em si, mesmo um dever" e, por isso, está livre de todas as barreiras, na medida em que "sua presença numa cabeça não pode causar dano a ninguém e a parte dela que alguém tem não reduz a parte - real ou possível - de outro" (TME, 101). A verdade conta com uma irrestrita liberdade porque ela é um valor em si, é sempre uma experiência que enriquece os seres humanos, pois a parte dela que é posse de um indivíduo "aumenta inclusive a parte potencial de todos os demais". A sociedade, nesse sentido, não deve construir barreiras para impedir o acesso à verdade. Entendendo que a empresa da verdade é o mote central da pesquisa em geral, Jonas vê nela um direito e um dever que devem permanecer no campo da plena liberdade, tanto de aquisição quanto de comunicação (com exceção do que ele chama de "direito aos segredos pessoais"). Não há problema em si na investigação, não há um problema moral aí, e sendo o conhecimento o único valor da ciência, então não haveria preocupação moral cabível, desde que essa busca estivesse orientada pelos pressupostos daquilo que poderíamos chamar de "cientificidade" (trabalhar com dedicação, ater-se ao método, não mentir, não enganar, não omitir dados, verificar a veracidade dos resultados, comunicá-los com rigor e clareza... - “ $\mathrm{em}$ suma, retidão e seriedade intelectuais" [TME, 102]). Haveria, portanto, uma única norma que diz respeito ao âmbito interno da própria ciência e exige do bom cientista que ele seja, afinal, simplesmente, um bom cientista. Desse ponto de vista, diz Jonas, "a ciência constitui uma ilha moral" (TME, 103). Contudo, ao tratarmos da ciência moderna, isso não é de todo verdade ou suficiente. Tal coisa valeria para a época em que conhecer era sinônimo de contemplar, não agora, em que o saber se transformou, sobretudo, em um ato exploratório, interventor e supostamente melhorista. Se no passado tratava-se de "entender as coisas, não de as modificar" e se o conhecimento era uma espécie de "estado de espírito", isso mudou substancialmente na modernidade e, com isso, abriu uma nova dimensão para a relação entre ciência e valores.

\section{Da teoria à prática}

A reivindicação de liberdade, por parte da ciência moderna se espalhou como ideal a todos os âmbitos da cultura, algo que tomou proporções cada vez maiores com as promessas e benefícios trazidos pela utilidade prática do saber, cujo primeiro grande serviço foi expresso pela Revolução Industrial e hoje o é pela tecnologia em geral. Desde então, "vivemos um transbordamento cada vez mais irresistível da teoria, por mais 'pura' que seja, para o campo vulgar da prática em forma de teoria científica" (TME, 105), transformada agora em um poder de ampla influência sobre as mais variadas condições e formas de vida. Dito de outra maneira, a ciência deixou de ser uma teoria, de cunho contemplativo e passou a assumir o âmbito da ação - e é justamente aí que ela não pode mais usufruir da irrestrita liberdade, ao contrário, como ação, ela precisa da ética, essa área do conhecimento que deve estar presente sempre que a ação do ser humano contenha o risco de afetar o mundo à sua volta - e isso ocorre sempre, já que todo agir humano é marcado pela ambiguidade e pela ambivalência, ainda mais no caso da tecnolgia moderna, quanto tal ambivalência é somada à magnitude inédita dos poderes. Para Jonas, portanto, "já não [estamos diante apenas de] uma questão de boa ou má ciência, mas de bons ou maus efeitos da ciência" (TME,102), já que não há ciência isenta de intervenção e sendo assim, é necessário perguntar sobre os seus reais benefícios, seus riscos e eventuais méritos.

Deveríamos, então, em nome da técnica, ou seja, da atividade interventora, julgar a ciência? Jonas afirma que uma visão simplista dos fatos levaria a supor que o pesquisador geralmente não tem responsabilidade sobre a aplicação de suas descobertas e, por isso, estaria isento de qualquer

OLIVEIRA, Jelson Roberto de.; SOUZA, Grégori de. A ciência pode tudo? Considerações éticas sobre tecnobiociência e valores a partir de Hans Jonas. Griot : Revista de Filosofia, Amargosa - BA, v.21 n.3, p.164-173, outubro, 2021. 
abuso ou dano causado por elas, pois "seu produto é o conhecimento e nada mais" (TME, 106). Por consequência, o produto do conhecimento seria, então, um bem disponível para quem quisesse usufruir dele do modo como bem entendesse e arcando com a responsabilidade sobre os seus atos. A ciência e os cientistas, seriam inocentes diante das consequências do seu uso. O exemplo a que Jonas recorre é o dos pesquisadores atômicos depois de Hiroshima, para afirmar que essa perspectiva é "plausível, mas demasiado simples", dado que os limites entre a teoria e a prática se tornaram não apenas "imprecisos" como também fundidos, de modo que não é possível falar em "ciência pura" e sequer presumir sua inocência diante dos fatos graves que resultam de seu uso. Isso porque, à exceção da cosmologia (no geral os objetos do cosmos não são passíveis de intervenção, embora hoje tenhamos avançado bastante nesse âmbito ${ }^{6}$ ), não há, hoje, ciência sem intervenção direta no seu objeto de conhecimento, ainda mais se levarmos em conta os interesses alheios que a orientam, dado que o ideal da ciência pura desaparece e em seu lugar surge a ideia de ciência como "ação social".

Outro problema ao qual Jonas se atém é sobre "como o cientista obtém seu saber" (TME, 108), isto é, sobre os instrumentos técnicos com os quais precisa contar para o seu trabalho de pesquisa. $O$ conhecimento chega, agora, através dos experimentos, ou seja, das intervenções e não da mera contemplação: dado que o patamar das coisas mudou, então o benefício da liberdade, que era próprio da aquisição do conhecimento na era pré-moderna, já não pode mais ser acessado por um saber que se revela como fazer através da intervenção sobre o mundo. Os novos instrumentos tiraram dos experimentos a inocência em termos de magnitude de seus impactos. Agora, experimentar não é mais imitar fenômenos naturais em pequena escala; os novos aparelhos tecnológicos tornaram possível que o experimento afete de forma irreparável novas dimensões globais em termos espaço-temporais. Para Jonas, "o mundo mesmo se tornou um laboratório" no qual o que é verificado, depois de ter sido realizado, pode levar à conclusão de que não deveria ter sido feito, embora sempre seja tarde demais para isso. Com efeito, em resumo, isso ocorre porque se diluíram as fronteiras entre pesquisa básica e pesquisa aplicada, entre teoria e a sua aplicação.

\section{A tecnobiociência e os desafios bioéticos}

Jonas lembra, além disso, os casos mais graves nos quais a irrestrita liberdade de pesquisa alcançou o auge do horror: os campos de concentração nazistas. Para ele, nesse caso, a liberdade foi muito mais vergonhosa do que a pior repressão poderia ter sido. Esse não é, contudo, o único exemplo. Há inúmeros outros casos em que a reprovação não é tão óbvia, como os casos de experimentos com seres humanos, com fins supostamente desejáveis realizados nos Estados Unidos na década de 1960 e 1970, citados por Jonas como parte de suas preocupações com o avanço da biologia nuclear e do campo biomédico em geral, áreas nas quais, consoante Jonas, a problemática da liberdade da pesquisa se apresenta de forma mais evidente e urgente porque, para ele, "o recém-chegado ao cenário da pesquisa básica, "a pesquisa com DNA recombinante" seria um "exemplo inquietante" (TME, 112), nos quais realidades novas podem se emancipar do seu criador. Jonas analisa passo a passo essa nova tecnologia com o fim de comprovar sua argumentação: o objetivo da pesquisa é prático, o método ocorre como produção de novas entidades as quais são os objetos do conhecimento, as entidades criadas são vivas e ativas, ou seja, capazes de entrar por si mesmas na esfera práticas e, com isso, as recombinações genéticas, como sínteses artificiais de novos organismos, podem realmente sair do controle humano.

\footnotetext{
6 Jonas acrescenta: “É digno de reflexão, e certamente não é casualidade, que a primeira de todas as ciências, a astronomia 'contemplação' do céu -, seja também a última ciência natural que continue sendo 'pura', isto é, inteiramente 'contemplativa" (TME, 107).
} 
A tecnobiociência é, por isso, um tipo de fazer científico que, unindo teoria e prática, adentra na "mecânica mais íntima da vida" (TME, 114) de forma temerária, embora amparada por justificativas cada vez mais evidentes a respeito de seus benefícios e "bênçãos potenciais". No que tange à articulação entre ciência e técnica, a recombinação genética de DNA apresenta-se como um caso bastante novo (Jonas fala disso na segunda metade do século XX), na medida em que a pergunta sobre a vida não é mais uma pergunta sobre o que existe agora como vida, mas sobre o que a vida poderia ser. Para Jonas, as novas "criaturas" guardam uma "promessa prática preconcebida": "ninguém duvidará que o verdadeiro atrativo está em saber o que podem fazer estas novas criaturas, o que nós poderíamos fazer depois com elas" (TME, 114). Ou seja, trata-se de um saber claramente orientado a um fazer, ou seja, à "consecução de efeitos" - e, sendo assim, levando-se em conta a argumentação anterior, por ultrapassar o âmbito da teoria pura, não poderia ocorrer de forma irrestritamente livre. A vida, nesse sentido, quando aparece como um novo campo de pesquisa, especialmente a partir do século XIX, já se coloca como um problema ético ou, mais especificamente, bioético.

O problema reside, precisamente, em que, para testar se tais promessas são factíveis, será preciso, primeiro, criar tais seres. Ou seja, para que a recombinação do DNA mostre sua utilidade prática, é preciso lidar com o "fato consumado" e não apenas com promessas. Para isso, "nenhum modelo de simulação pode servir" (TME, 115) e nem sequer a imitação serve de método, pois é preciso inventar um novo ser, ou seja, a pesquisa deve, primeiro, criar seu próprio objeto para, só então, ser capaz de comprovar suas teses iniciais. $O$ experimento torna-se o terreno fértil para tal comprovação: conhecer é produzir algo novo, de forma original. Qual é o problema? É que "a realidade assim criada - diferentemente de outros artefatos -, esse novo ser inserido na existência, está vivo" (TME, 115), ou seja, é uma vida ao mesmo tempo "autônoma, autorreprodutiva e espontaneamente interativa com outra vida", prestes, portanto, a sair do "laboratório", isto é, a fugir das rédeas do controle científico (seja por acidente ou por intenção) e se tornar um agente no mundo, cujas consequências, a partir daí, tornam-se "irrevogáveis".

Jonas lembra que, por isso, os próprios cientistas declararam, nos anos 1970, uma moratória - a primeira delas, na Conferência de Asilomar, para que fossem criadas diretrizes para a utilização das novas técnicas. Dito de outra maneira, os próprios cientistas reconheceram que não é possível falar de uma liberdade irrestrita no campo das pesquisas com a vida, embora não tenha demorado para que os interesses comerciais e industriais, "menos sensíveis aos escrúpulos dos medrosos cientistas" (ou mesmo cientistas mais ambiciosos que se tornaram empresários) passassem a orientar tais investigações.

\section{Considerações finais}

Centrando as suas preocupações na relação entre a o saber e o fazer, a ciência e a técnica e, entre a tecnologia e a ética, Jonas desenvolve a aplicação de suas teses sobre a responsabilidade sobre o campo dos progressos tecnocientíficos. Com isso, levanta como uma das questões centrais, precisamente o problema da liberdade absoluta, reivindicada pelos agentes tecnológicos como meio de legitimação de suas promessas que, segundo o próprio Jonas, guardam atributos quase escatológicos que reúnem promessas utópicas e ameaças apocalípticas.

Sua reflexão, por isso, serve para comprovar que, na atualidade, a distinção entre teoria e prática é uma ficção e a reivindicação de liberdade ilimitada por parte da ciência, um perigoso equívoco, quando se leva em conta o bem público e o bem de toda a comunidade da vida. Jonas projeta, portanto, a importância nuclear do pensamento bioético contemporâneo, sem o qual a ciência se tornará uma arma absolutamente perigosa. A "vontade de ilimitado poder" que isso carrega, tem como uma das premissas centrais, na descrição jonasiana, a "liberação utópica do

OLIVEIRA, Jelson Roberto de.; SOUZA, Grégori de. A ciência pode tudo? Considerações éticas sobre tecnobiociência e valores a partir de Hans Jonas. Griot : Revista de Filosofia, Amargosa - BA, v.21 n.3, p.164-173, outubro, 2021. 
animal humano de toda necessidade material" (TME, 34), tal como propõe, por exemplo, o marxismo. Liberar o homem de suas necessidades materiais corresponde, assim, a liberar o homem dos limites impostos pela própria natureza - algo, aliás, bem mais profundo quanto a suas consequências. Nessa ótica, qualquer aperfeiçoamento dos seres vivos (que inclui a manipulação e a modificação genética, os avanços da biologia sintética e do controle neurológico e fármacoquímico dos comportamentos, por exemplo) revela-se como uma luta contra a natureza, seja a natureza das coisas em geral, seja a natureza humana em particular. E como toda luta, também essa precisa seguir orientando-se por valores fundados no bem comum - um bem que inclui, como Jonas insistiu, o bem de todas as formas vivas. 


\section{Referências}

BECCHI, P. La vulnerabilità dela vita: contributi su Hans Jonas. Napoli: La Scuola di Pitagora Editrice, 2008.

DUMIT, J. "A digital image of the category of the person. PET scanning and objective self fashioning". In: DOWNEY, Gary Lee \& DUMIT, Joseh (eds.). Cyborgs and citadels. Anthropological interventions in emerging sciences and technologies. Santa Fe: School of American Research Press, 1997.

JONAS, H. Técnica, medicina e ética. Sobre a prática do princípio responsabilidade. Tradução do Grupo de trabalho Hans Jonas da ANPOF. São Paulo: Paulus, 2013 (Col. Ethos).

JONAS, H. O princípio responsabilidade: ensaio de uma ética para a civilização tecnológica. Trad. Marijane Lisboa, Luiz Barros Montez. Rio de Janeiro: Contraponto: Ed. PUCRio, 2006.

OLIVEIRA, Jelson. Da magnitude e ambivalência à necessária humanização da tecnociência segundo Hans Jonas. Cadernos IHU Ideias (UNISINOS), v. 176, 1-20, 2012.

Contribuição dos(as) autores(as) / Author's Contributions: Jelson Roberto de Oliveira e Grégori de Souza realizam pesquisa conjunta, junto ao Centro Hans Jonas Brasil e à Cätedra Hans Jonas da PUCPR. Esse artigo é parte dessa pesquisa, que inclui também uma dissertação de mestrado. Nesse artigo, trabalhou-se conjuntamente na estratégia teórica e na redação do texto. Tratou-se de um trabalho efetivamente conjunto, com leituras e correções, debates e redação realizada de forma conjunta. Ambos(as) os(as) autores(as) aceitaram e aprovaram a versão final do texto

Autor(a) para correspondência / Corresponding author: Jelson Roberto de Oliveira. jelsono@yahoo.com.br 